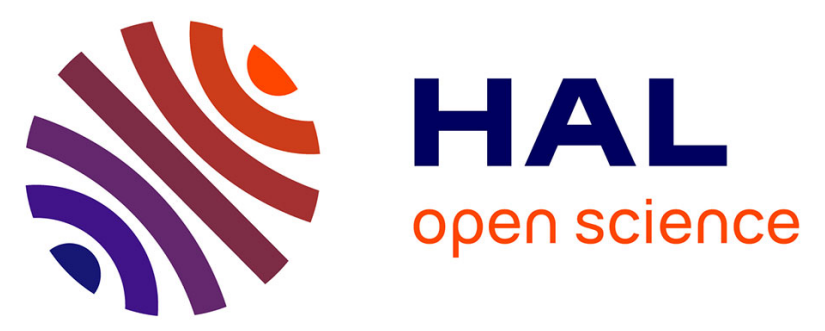

\title{
Evidence of Subliminally Primed Motivational Orientations: The Effects of Unconscious Motivational Processes on the Performance of a New Motor Task
} Rémi Radel, Philippe Sarrazin, Luc Pelletier

\section{- To cite this version:}

Rémi Radel, Philippe Sarrazin, Luc Pelletier. Evidence of Subliminally Primed Motivational Orientations: The Effects of Unconscious Motivational Processes on the Performance of a New Motor Task. Journal of Sport and Exercise Psychology, 2009, 31, pp.657-674. 10.1123/jsep.31.5.657 . hal00401726v2

\author{
HAL Id: hal-00401726 \\ https://hal.science/hal-00401726v2
}

Submitted on 23 Sep 2009

HAL is a multi-disciplinary open access archive for the deposit and dissemination of scientific research documents, whether they are published or not. The documents may come from teaching and research institutions in France or abroad, or from public or private research centers.
L'archive ouverte pluridisciplinaire HAL, est destinée au dépôt et à la diffusion de documents scientifiques de niveau recherche, publiés ou non, émanant des établissements d'enseignement et de recherche français ou étrangers, des laboratoires publics ou privés. 
Running head: UNCONSCIOUS MOTIVATIONAL ORIENTATIONS

\section{Evidence of Subliminally Primed Motivational Orientations:}

The Effects of Unconscious Motivational Processes on the Performance of a New Motor

Task

Rémi Radel, Philippe Sarrazin

University of Grenoble, France

Luc Pelletier

University of Ottawa, Canada

Journal of Sport and Exercise Psychology (2009)

31, 657-674.

Submitted: February 23, 2009

Revised: May 4, 2009

Accepted: July 3, 2009

Mailing addresses:

Rémi Radel (Remi.Radel@bvra.e.ujf-grenoble.fr) and Philippe Sarrazin (philippe.sarrazin@ujfgrenoble.fr), Laboratoire Sport et Environnement Social, Université Joseph Fourier, UFRAPS, BP 53, 38041 Grenoble cedex 9, France. Luc Pelletier (Luc.Pelletier@uOttawa.ca), School of Psychology, University of Ottawa, 200 Lees - C101 0 ttaw a, 0 n ario K 1 N 6 N5 , Canada. 


\begin{abstract}
The aim of this study was to examine whether motivational orientations for a new motor task could be triggered by unconscious determinants. Participants were primed with subliminal words depicting an autonomous, a neutral, or a controlled motivation during an initial unrelated task, followed by working on an unknown motor task. Behavioral, physiological and selfreported indicators of motivation for this task were assessed. Overall, results indicated a significant impact of the priming condition on all these indicators; while the priming of autonomous motivation led to positive outcomes, the priming of controlled motivation led to negatives outcomes when compared to the neutral condition. Implications regarding the priming of unconscious determinants of motivation for sport and exercise are discussed.
\end{abstract}

Keywords: motivational orientation; self-determination theory; subliminal priming; unconscious processes. 
Most contemporary motivational theories more or less directly rely on what Weiner called more than 25 years ago “the godlike metaphor” (Weiner, 1992). This metaphor was used to characterize a theoretical assumption that individuals are perfectly rational, all knowing, aware of goals and that they are pursuing all possible alternatives to goal-related actions. The Theory of Planned Behavior (Ajzen, 1991) is a striking illustration of such a "rational model”. This theory postulates that behaviors are directly predicted by conscious intentions, which are themselves the result of a reasoning process based on a set of conscious beliefs. Multiple theories of goal pursuits (e.g., Bandura, 1986; Carver \& Scheier, 1998; Locke \& Latham, 1990) also consider that goals are consciously set and require an attentive process of self-regulation. Finally, the SelfDetermination Theory (SDT; Deci \& Ryan, 1985), which has gained popularity over the last 20 years and which is widely applied to sport and exercise (see Hagger \& Chatzisarantis, 2007, for a review), also implies such deliberative processes. SDT postulates a distinction among motivational orientations depending on the perceived locus of causality which requires a conscious evaluation of the situation and of the reasons to act (Deci \& Ryan, 1985). Taken together, conscious appraisal is presumed to be a fundamental mechanism by the most influential motivational theories today.

However, during the last decade, some theoretical models have emerged from various psychological sciences including neuroscience (e.g., Lieberman, 2007), cognitive psychology (e.g., Metcalfe \& Mischel, 1999), social cognition (e.g., Strack \& Deutsch, 2004), personality (Epstein, 1994) and social psychology (e.g., Chaiken \& Trope, 1999), that unanimously acknowledge both a conscious and an unconscious system responsible for behavior. Although each of these models used different labels to denominate the highlighted systems (e.g., automatic vs. controlled, impulsive vs. reflective, hot vs. cool), all of them make a distinction between a 
system in which cognitive processes are deliberative and mobilize attention and a system in which processes are automatically processed outside of awareness. These two systems are described as having different operating modes and different functions. Briefly, the conscious system generates behavioral decisions based on knowledge about facts and values by using semantic processing which requires a high amount of cognitive resources. The unconscious system, by contrast, is described as continuously working and able to efficiently process a mass of stimuli by using an associative method based on previously established links to elicit behaviors. These models assume that while the conscious system seems devoted to learning novel behaviors and to managing complex situations, the unconscious system seems, in contrast, devoted to managing acquired actions and performing simple actions. Research conducted in social psychology has shown that the unconscious system is however not only involved in basic cognitive functions but also in higher mental processes, such as social judgment (e.g., Uleman, Newman, \& Moskowitz, 1996), decision making (e.g., Dijksterhuis, Bos, Nordgren, \& Van Baaren, 2006), and motivational processes (e.g., Bargh, 1997).

More specifically, with the exception of research on implicit motives (McClelland, Koestner, \& Weinberger, 1989), the modern investigation of the motivational unconscious has mainly focused on the automatization process. The Auto-Motive model was specifically created by Bargh (1997) to explain how the unconscious system can take the place of the conscious system when a motivational response gets automatized. According to this model, the different motivations are represented in memory like any other knowledge, emotions, or attitudes. These motivations are connected to other constructs via past experiences. Thus, if people consciously select the same motivation in a specific context many times, then a neural connection is created between the motivation and any elements of this particular context (Shiffrin \& Dumais, 1981). 
With automatization of this motivation, the motivational process is progressively delegated to the unconscious system, which will trigger an automatized motivation every time one of these contextual elements is perceived. For example, someone who learned how to swim in a very controlling climate (i.e., he/she is pressured by others to go to the swimming pool) may have developed over time a controlled motivation for that activity. Consequently, it is likely that every time an event related to this activity subsequently occurs in the life of this person (e.g., the sight or the smell of a swimming pool), controlled motivation would be automatically activated leading him/her to avoid this activity or to approach it only for external reasons. In the same vein, because engagement in an activity by choice, interest, or preference is associated over time with optimal functioning, any environmental cues which could awake feelings of freedom, choice, or volition may entail a positive mindset conducive to adaptive behaviors (e.g., more positive attitude towards the task, more effort and more persistence) in subsequent tasks.

Bargh and his colleagues (e.g., Bargh, Gollwitzer, Lee-Chai, Barndollar, \& Trötschel, 2001; Chartrand \& Bargh, 1996) have experimentally tested the Auto-Motive model using the priming paradigm. This paradigm emphasizes the connectionism proprieties of memory to unconsciously activate a mental construct by exposing participants to stimuli (i.e., prime) connected to the motivational construct of interest. Typically, a priming experiment is divided in two successive phases, with the first task devoted to the activation of the construct and the second task devoted to the observation of priming consequences. Specifically, the level of accessibility of an available construct stored in memory is temporarily raised in the first task using related stimuli, so that it can be readily applied to a subsequent situation and influence ensuing behaviors, emotions or thoughts. Most of the time, the two tasks are completely different, and the experimenter even emphasizes that the two tasks are unrelated as it is important 
that participants believe that what they perceived in the first task has no influence on what they do in the second task. A priming experiment can be either carried out with subliminal or supraliminal stimuli (Bargh \& Chartrand, 2000). Subliminal stimuli literally mean stimuli below the limen (i.e., the threshold from which individuals can report the perception of the stimuli). Thus, in a subliminal priming experiment, participants are exposed to stimuli which are physically present but not consciously detected (Dijksterhuis, Aarts, \& Smith, 2005). Although many subliminal techniques exist, the most common one is to use a very brief exposure to visual stimuli. In a supraliminal priming experiment, participants consciously perceive the primes during their exposure, but are unaware of the influence that these stimuli have on their behavior. Many priming studies provide strong support for the Auto-Motive model, demonstrating that motivational goals can be automatically triggered outside of participants' awareness (see Ferguson, Hassin, \& Bargh, 2007, for a review). However, previous research has mainly focused on proximal goals (e.g., helping others, cleaning, or earning money) and only two articles have examined priming of wider motivational orientations like those advocated by SDT (Hodgins, Yacko, \& Gottlieb, 2006; Lévesque \& Pelletier, 2003). More precisely, these studies examined the automaticity of autonomous and controlled motivations. According to SDT, an autonomous motivation corresponds to an experience of volition and self-endorsement of actions. In other words, when people are autonomously motivated, they freely chose to initiate their behavior and engage in activities that promote fulfillment of the innate psychological needs for autonomy, competence and relatedness. Examples of autonomously motivated behavior would be doing an activity on the basis of interest, challenge, positive feelings and growth. By contrast, people who have a controlled motivation experience pressure to behave in particular ways. Doing an activity for instrumental reasons, such as external rules, or the expectation of a reward rather than for the 
satisfaction derived from the activity itself are examples of such motivation (Deci \& Ryan, 1985).

Knowing whether or not these motivational orientations can be unconsciously triggered is a very intriguing question. Indeed, ‘autonomous' and 'controlled' motivations are global motivational orientations that represent a more general propensity or mindset. There is very limited evidence suggesting such abstract motivational constructs are represented in memory. Since the representation of a construct in memory is the minimal criterion for automaticity (Higgins, 1996), we can wonder whether these motivations can be automatically activated.

For instance, Lévesque and Pelletier (2003) as well as Hodgins et al. (2006) have primed autonomous and controlled motivations via a supraliminal exposition of stimuli. More precisely, in these experiments, participants initially completed a scrambled sentences task presented as an independent psycholinguistic experiment. In one condition, the majority of the sentences corresponded to an autonomous motivation (e.g., "he is feeling autonomous”), and in the other condition the majority of sentences corresponded to a controlled motivation (e.g., "he has an obligation”). In a second, ostensibly unrelated part of the experiment, primed motivational orientations produced effects that are similar to those that are usually reported when these motivational orientations are consciously adopted. More specifically, when participants of the Lévesque and Pelletier’s (2003) study were asked to solve puzzles, those primed with autonomous motivation expressed more interest, more choice, performed better and persevered longer during a subsequent crossword activity than participants primed with controlled motivation. Furthermore, these effects occurred without any awareness or knowledge of the connection between the priming task and the puzzle task as revealed in a funneled debriefing (see Bargh \& Chartrand, 2000, for a more accurate description of this debriefing procedure). 
Hodgins et al.’s (2006) studies focused more specifically on the effects of autonomous and controlled motivation on defensiveness (i.e., protection of the self based on avoidance strategies). In three studies, they found that participants primed with autonomous motivation demonstrated less defensive attitudes (i.e., lower desire to escape, lesser self-serving bias and self-handicapping utilization) than participants primed with controlled motivation. Interestingly, their third study took place in a sport context. Participants were members of a rowing team and their rowing performance was assessed subsequent to the priming procedure. Their results indicated that participants primed with autonomous motivation rowed faster than participants primed with controlled motivation.

Although these findings are consistent, indicating in both cases an assimilation of the primed motivational orientation, we think that additional elements are required to provide more compelling evidence of unconscious motivational orientations. In addition to the fact that only two articles reported these findings, both used the same supraliminal priming method to activate the construct of interest. The supraliminal priming is however not the more reliable method to rule out any alternatives of conscious processes. For instance, when supraliminal is used, only the debriefing can ensure that the effect was really unconscious. Several elements may nevertheless limit validity of this procedure. As Dixon (1981) pointed out, participants may forget a conscious thought that they had. Consciousness continuously generates thoughts, which are mostly not planned to be memorized and which might therefore be hard to report after a while. Furthermore, divergent findings have been reported when researchers primed the same construct using supraliminal or subliminal stimuli (e.g., Gillath, Mikulincer, Birnbaum, \& Shaver, 2008). Therefore, at least under certain circumstances, supraliminal and subliminal priming does not refer to the same mechanisms (see also Merikle \& Daneman, 1998). 
The purpose of the present study is to provide more evidence that autonomous and controlled motivations can be automatically triggered outside of awareness by using subliminal stimuli. Words related to the experience of being autonomously motivated versus controlled were embedded in a distracting cognitive task. The effects of such primed motivational orientations were then examined on a new motor task requiring effort. Several behavioral indicators of motivation (e.g., performance, perseverance, effort, and free-choice involvement) were taken into account to have a more comprehensive view of the consequences of priming. Moreover, in order to determine the extent and the direction of the effect of primed motivational orientations we included a third control group, which was only primed with neutral stimuli.

Our intent was to determine if automatically triggered motivational orientations, once activated, produce effects that are exactly the same as those that are consciously selected. Previous studies in sport and exercise contexts have shown that autonomous motivation had more positive consequences than controlled motivation, leading to more perseverance and less drop out in sport (e.g., Pelletier, Fortier, Vallerand, \& Brière, 2001; Sarrazin, Vallerand, Guillet, Pelletier, \& Cury, 2002), greater free-choice involvement and performance in exercise (e.g., Vansteenkiste, Simons, Soenens, \& Lens, 2004), more effort and performance in physical education (e.g., Boiché, Sarrazin, Grouzet, Pelletier, \& Chanal, 2008), and higher participation in optional physical education activities (Ntoumanis, 2005).

Based on these findings, we expected that participants primed with autonomous motivation would (1) persevere more and that they would invest more effort during the learning period of the new motor task, (2) that they would perform better in a performance test and that they would persist longer in a free-choice period, and finally, (3) that they would report more interest and more satisfaction of their need for autonomy, in comparison to participants primed 
with controlled motivation. We also expected that the scores of the control group on these dependent variables would end up between the two experimental groups on all indicators of motivation. In other words, we expected a linear pattern for all our results.

Method

\section{Participants}

The initial sample consisted of 75 French undergraduates students (30 females and 45 males: $M=20.5 \pm 1.3$ years) from the Sport Sciences department of the University of Grenoble, who participated on a voluntary basis. All of these participants had never practiced the experimental motor task, as attested by a preliminary question. They were randomly divided into three equal groups depending on the experimental conditions. The distribution of females and males was balanced within these groups. Approval of the study protocol was obtained from the ethics committee of the university.

\section{Procedure}

Participants were informed that they would take part in two unrelated experiments. Since several academic disciplines are taught in the faculty of sport sciences, participants were told that the first experiment was related to psychology and the second one to physiology. In order to increase the realism of this cover story, two different (but adjacent) rooms and two different experimenters were used. Participants completed the experimental session individually. Prior to completing the experimental session, a consent form which included a description of the experimental tasks was completed by participants.

The priming task. Upon entering the laboratory, participants met the physiology experimenter (the experimenter's gender was matched to the participant's gender). The experimenter then set up the cardiac sensor required for the physiology experiment while 
participants were waiting for the arrival of the experimenter for the psychology experiment. Then, the experimenter led participants into the psychology room experiment. They were seated in front of a computer and were asked to wait quietly for the psychology experimenter. Three minutes after, he/she entered the room and explained that the goal of the experiment was to examine memorization processes and described the experimental task to the participant. All instructions were provided by a computer endowed with a cathodic screen set at a 15 ms refresh rate, and with E-Prime ${ }^{\circledR}$ software. Participants were asked to identify as soon as possible if two pictures were the same or if they were different. A computer function randomly assigned participants to one of the three conditions: autonomous motivation, controlled motivation, or neutral ( $\mathrm{N}=25$ in each condition). The procedure ensured that the experimenter was kept unaware of participants’ priming condition. A subliminal word was inserted just before each picture was displayed. Words were randomly chosen by the software to produce a series of four words. In the autonomous condition, the words were: envie, volonté, liberté, choisir (desire, willing, freedom, chose). In the controlled condition the words were: contraint, obligation, devoir, obéir (constrained, obligation, duty, obey). Words were chosen according to the previous studies using words to characterize motivational orientations (e.g., Lévesque \& Pelletier, 2003; Ryan \& Connell, 1989). In accordance with many priming studies (e.g., Aarts, Chartrand, Custers, Danner, Dik, Jefferis et al. 2005) primes for the control group were strings of letters without meanings to avoid the activation of unwanted constructs which could be primed if meaningful words were used as neutral primes.

A total of 92 primes for each condition were displayed. Subliminal words were flashed in the parafoveal vision area (see Bargh \& Chartrand, 2000). For that, a fixation point located at the center of the screen was used before the prime and the location of the prime was randomly 
presented in one of the four quadrants of the screen (Chartrand \& Bargh, 1996). The stimulus word was presented for 45 ms and was immediately followed by a 60 ms mask (i.e., “apmsgz”) at the same location. A trial began with a $1 \mathrm{~s}$. fixation point followed by the prime and the mask, and the first picture for $5 \mathrm{~s}$. Then, the same fixation point came back followed by the prime and the mask which appeared just before the second picture. This one disappeared when participants answered. The trial finished with feedback indicating only the response time in order to avoid feelings of success or failure. This task consisted of 46 trials and the average time for the completion was about 12 min. When the task was completed, participants were thanked and asked to leave the room.

The motor task. Immediately after participants left the room, they were led into the other room by the physiology experimenter. A hidden camcorder recorded all the sessions in this room. Participants were told that the purpose of this experiment was to study the relationship between cardiovascular and muscular activity. They were asked to learn how to use a powerball® in a 15 min. period, with the help of two pedagogic documents: a 55 seconds video and a poster indicating tips for quickly learning this activity. The powerball@ is a gyroscopic exercise task which consists of a tennis ball-sized plastic shell around a free-spinning mass (i.e., the rotor). It works without electricity starting with a string impulsion. A circular movement of the wrist maintains and accelerates the spinning of the powerball ${ }$. Then, the activity quickly becomes physical, as a strong resistance appears when the rotor speed increases.

This motor task was chosen because (a) it was unknown to participants, therefore no a priori motivation could be associated with it, (b) it gives a reliable score of performance via a digital counter, (c) it requires sufficient physical effort to record physiological variations, and (d) as a function of prime, it can be either related to "fun” features because this entertaining sport 
instrument delivers sensations and emits sound and light, or either to "tedious" features because its use is drudgery at the beginning and quickly tiring afterward. In order words, the participant had the possibility to experience the activity as either a challenge and/or a fun discovery (i.e., autonomous motivation) or as a constraint and/or an obligation (controlled motivation).

At the end of the learning period, the experimenter came back and asked participants to perform two trials using a performance test. They were asked to rotate the powerball ${ }^{\circledR}$ as fast as possible. Then, the experimenter left participants alone under the pretext that he/she no longer had a copy of the printed questionnaire. During this time, participants were given the possibility to practice the activity again or to read a magazine. The initiation of an activity freely and without any external pressures has been used many times to assess self-determined motivation in different contexts (see Deci \& Ryan, 1985) including sport and exercise (see Vallerand \& Fortier, 1998, for a review). Four minutes later, the experimenter returned into the room and gave a form to the participant containing items assessing intrinsic motivation and the satisfaction of the need for autonomy.

Finally, as part of the debriefing, the experimenter carefully probed for any suspicions regarding the relation between the two tasks with a funneled questionnaire protocol (Bargh \& Chartrand, 2000). Four questions were verbally asked: (1) Can you precisely indicate what were the purposes of both experiments?, (2) Do you think that the two experiments were related to each other?, (3) Do you think that what you did in the first experiment influenced your involvement in the second task?, and (4) Did you notice something unusual during the computer task of the psychology experiment?. If a participant indicated a positive answer to one of the three last questions, he/she was asked to give a detailed answer. Then, the experimenter asked why participants performed the motor task. Finally, the experimenter revealed the true purpose 
of the study and provided explanations justifying the use of a masked presentation of the experiment in order to minimize deception. A second informed consent summarizing these points and asking permission for data use was provided to the participants.

\section{Measures}

Performance on the motor task. A digital counter situated on the shell of the powerball@ indicated the speed rotation of the rotor in rotations per minute (RPM). Only the best score of the two trials for the performance test was maintained.

Perseverance during learning period. From video-recorded material, a judge blind to the conditions counted the amount of time (in seconds) during which the participant used the powerball®.

Involvement during the free-choice period. The same judge, counted the total time (in seconds) that participants used the powerball ${ }^{\circledR}$ during the free-choice period.

Invested effort during the learning period. Given the linear relation between the intensity of work and heart rate (e.g., Astrand \& Rodahl, 1986), an index of energy resources provided by the participant to train on the powerball® ${ }^{\circledR}$ was given by the increasing percentage between the resting heart rate and the mean heart rate during the training period (e.g., Sarrazin, Roberts, Cury, Biddle, \& Famose, 2002). Thus, this index provided a control for individual differences in heart rate and took into consideration the effort invested during the total time of the training period. The heart rate was continuously recorded with an ambulatory device (Actiheart ${ }^{\circledR}$ sensor; Cambridge Neurotechnology Ltd). This lightweight instrument was strapped onto the chest. The data were analyzed by the program provided with the instrument (Actiheart ${ }^{\circledR}$ version 2.2 software). The resting heart rate value was obtained when the participant was waiting for the psychology experimenter at the beginning of the study. 
Interest/Enjoyment. Eight items (e.g., "I enjoyed this activity very much", $\alpha=.83$ ) of the subscale of the Intrinsic Motivation Inventory (IMI; Ryan, 1982) assessed the individual’s perception of interest-enjoyment with the motor task. Participants answered these items on a 7point Likert scale, ranging from (1) “do not agree at all” to (7) “completely agree”.

Autonomy satisfaction. The autonomy (e.g., "I felt free to exercise in my own way", $\alpha=$ .82) subscale of the French version of the Needs Satisfaction Scale adapted for sport and exercise settings (Gillet, Rosnet, \& Vallerand, 2008) was used. This subscale includes five items rated on a 7-point Likert scale, ranging from (1) “do not agree at all” to (7) “completely agree”.

\section{Data Analyses}

Four participants (5.33\%) expressed some suspicion about the experimental manipulation and were removed from the analyses. Two of them suspected that the two experiments were not completely independent and two reported seeing blinking on the screen and then hypothesized the use of a subliminal technique. Thus, all participants in the final sample were unaware of the experimental manipulation as they indicated (1) similar study purposes as those told by the experimenters, (2) no relationship between the two experiments, and (3) no notable elements in the first experiment.

We first examined whether a multivariate effect was induced by the priming manipulation using a generalized linear model analysis. Then, we examined specificity and direction of the effect using univariate regression models. According to Rosenthal and Rosnow (2008), we created two contrasts to test our hypothesis. The first contrast translated into the expected linear effect. Specifically, we assigned weights of $-1,0,+1$ respectively to the controlled, neutral, and autonomous conditions. The second contrast was a quadratic contrast, orthogonal to the first one (i.e., the controlled, autonomous, and neutral conditions were respectively assigned the weights 
of $-1,-1$, and +2$)$. This second contrast had no specific meaning relative to our hypotheses, but it allowed us to examine the potential existence of a residual effect after controlling for the variance explained by the first contrast. Two criteria are indeed required to conclude the presence of the expected linear effect: (1) the linear contrast is significant, (2) the quadratic contrast representing the residual variance is non-significant (e.g., Brauer \& McClelland, 2005; Rosenthal \& Rosnow, 2008). Given that perseverance during the learning period and involvement during the free-choice period presented an asymmetric distribution (skewness > $|2|$ ), a reverse transformation (see Tabachnick \& Fidell, 2006) was conducted on these two variables, which rectified the deviation from normality (skewness $<|1|$ ).

Results

Table 1 displays zero-order correlation of all dependent variables. Logically, the longer participants practiced the motor task during the learning period, the higher their mean heart-rate was $(r=.28, p<.05)$. Self-reported interest and enjoyment for the motor task was highly correlated with the self-reported autonomy satisfaction $(r=.72, p<.001)$, and marginally correlated with performance $(r=.21, p<.10)$ and involvement during the free-choice period $(r$ $=.20, p<.10)$.

Table 2 shows descriptive statistics of all dependent variables. For the sake of clarity, we present non-transformed means. Results of the multivariate analyses reveal a significant effect of a linear contrast, Wilks’ Lambda $=0.69, F(6,63)=4.83, p<.001$, and a non-significant effect of a quadratic contrast, Wilks’ Lambda $=0.91, F(6,63)=0.97, p=.45$. Six multiple hierarchical regression analyses were then performed for each motivational measure. In the first step of each regression analysis, dependent variables (DV) were regressed onto linear contrasts to test our hypothesis. In the second step, the quadratic contrast was entered in order to test the residual 
effect after controlling for the variance explained by the linear contrast. Results obtained from these analyses are presented in Table 3. They reveal that (1) linear contrast significantly predicts all DVs in the study, ts (68) $>2.12$, ps $<.05$, and (2) quadratic contrast is systematically nonsignificant, ts (68) < 1.72, ps > .10 and explains no additional variance after controlling for the variance explained by the linear contrast, Fs change $<2.90, p>$.10. In others words, each time the main part of the variance is explained by the first linear contrast. Clearly, participants primed with autonomous motivation performed better, invested more effort, persisted longer during the learning period and during the free-choice period, reported more interest and enjoyment for the activity and reported a higher level of autonomy, than participants primed with controlled motivation. As expected and as indicated in Table 2, scores of the neutral condition participants on all of these dependent variables were located between the two primed groups.

\section{Discussion}

The SDT is one contemporary theory that has become very popular in sport and exercise psychology research. For example, articles inspired by this theory represent $12 \%$ of the total research published in the Journal of Sport \& Exercise Psychology in the last three years. Its success can certainly be explained by the meaningful distinction between autonomous and controlled motivations. This distinction has indeed demonstrated a powerful predictor of a wide range of consequences in sport and exercise such as among others, perseverance (e.g., Pelletier et al., 2001), free involvement (e.g., Vansteenkiste et al., 2004), and effort and performance (Boiché et al., 2008). Because SDT, like many other motivational theories, mainly relies on conscious processes, it is usually presumed that the motivational orientation adopted in a new activity results from conscious thinking. 
In line with recent research on unconscious autonomous and controlled motivation (Hodgins et al., 2006; Lévesque \& Pelletier, 2003; see Lévesque, Copeland, \& Sutcliffe, 2008, for a review), the goal of the present study was to examine if both motivational orientations could be automatically triggered by unconscious determinants. Using several indicators of motivation for exercise, we observed that the priming manipulation had a general effect on involvement in a new motor task. A significant linear effect was found across all dependent variables indicating that both autonomous and controlled motivation conditions produced specific outcomes compared to a neutral group. Similar to the effect that is usually reported by the research on SDT's motivational orientations (see Hagger \& Chatzisarantis, 2007 for a review in sport and exercise), participants primed with an autonomous motivation displayed more adaptive responses while participants primed with controlled motivation displayed less adaptive responses in comparison to participants in the neutral condition. Specifically, when subliminal words displayed in an initial unrelated task referred to an autonomous motivation (e.g., wish, freedom) rather than a controlled motivation (e.g., constrained, duty), participants were more involved and invested more effort for learning a subsequent new motor task, as depicted by their time devoted to the activity and their increased heart rate. In addition, they performed better when they were evaluated and when they spent more time on the task during a free-choice period. Although participants were unaware of the unconscious determinants of their motivational orientation, results showed that they however realized the consequences generated by the subliminal manipulation. Participants primed with an autonomous motivation indeed reported more interest and enjoyment for the task and a greater satisfaction of their need for autonomy than those primed with a controlled motivation. 
Although these motivational indicators account for different facets of motivation as shown by the relatively weak correlation between these variables, we found that the effect of the manipulation was consistent across all of these indicators. The consistency of the effects and the medium to large effect size (mean $\beta=.30$; see Table 3 ) provided reliable evidence that motivational orientations such as those suggested by SDT can be activated outside of an individual's awareness. The present findings support previous studies by Lévesque and Pelletier (2003) and Hodgins et al. (2006) which demonstrated that supraliminal stimuli referring to motivational orientations subsequently influenced participants' behaviors in the same direction as the primed motivational orientations. Nevertheless, our study was the first to use a subliminal procedure to prime motivational orientations, ruling out any alternative hypothesis of conscious mechanisms for explaining the priming effect (e.g., Dixon, 1981; Merikle \& Daneman, 1998).

This unconscious influence on motivation is particularly fascinating in the context of a new motor task. Indeed, in this specific setting, deliberative processes of the conscious system are typically presumed to be much more prevalent than unconscious influences. One may think that involvement in a motor activity has to be consciously monitored because motor activities require the regulation of energy. Moreover, new activities are typically presumed to be controlled by the conscious system. For example, Ajzen (2002) indicated that: "Novel behaviors and unfamiliar situations are said to evoke careful deliberation and controlled production of beliefs, attitudes, and intentions that direct subsequent behavior” (p.109). In spite of that, we observed in the present study that individuals' motivation for a new motor task was influenced by unconscious processes. So one can wonder why the enhanced conscious monitoring generated by the new motor task did not annihilate the unconscious influences? Even though the conscious system is indeed able to moderate or to disrupt responses that are unconsciously selected 
(Norman \& Shallice, 1986), we think this control function did not occur because both primed motivation orientations would be appropriate for the task. Indeed, the conscious control function over unconscious influences has been reported when the impulse is not adapted to the situation, costly or displeasing (e.g., Macrae \& Johnston, 1998). Since participants could actually adopt either an autonomous motivation (e.g., practice the pleasure to discover a new activity) or a controlled motivation (e.g., just to obey to the experimenter doing a strenuous and boring activity) in this task, unconscious influences were not disrupted by consciousness.

In the future, it would be interesting to further investigate this process by examining the magnitude of the effect of primed motivational orientation based on the appropriateness of the primed motivational orientation in relation to the specific task. For example, we should examine if priming autonomous motivation can still work when the target activity is uninteresting and unnecessary for individuals or on the contrary, if priming controlled motivation can reduce motivation for an interesting activity.

Future research should also more closely examine the role played by psychological needs in automatic activation of motivational orientation. According to SDT, it is hypothesized that the motivational orientation is determined by the social context via the extent to which psychological needs for competence, autonomy, and relatedness have been fulfilled (see Vallerand \& Losier, 1999, for a complete description of this motivational sequence in sport). The results of the present study suggest that psychological needs are not the mediator with respect to the automatic activation of motivational orientations as there are almost no significant correlations between autonomy satisfaction and motivational consequences. Although it seems possible that the automatic activation of motivational orientations could be linked to a stimulus without any mediators (Dijksterhuis \& Bargh, 2001), it is also plausible that our measure of need satisfaction 
was simply not appropriate. Since the perception of the priming event was unconscious, it is possible that its impact on psychological needs was not accessible to introspection and thus, it could only be assessed by an implicit measure. Therefore, it appears important to determine in future studies whether the motivational sequence postulated by SDT is supported in the case of unconscious influence.

\section{Conclusion}

The results of the present study suggest that unconscious determinants can play a significant role in the activation of motivational processes. It is plausible that the results of this study are limited to the particular laboratory study design and therefore it is important that additional research be conducted to fully understand if and how unconscious motivational orientations could be primed in real-life settings. We hope that such findings will allow future research and intervention in sport and exercise psychology to pay more attention to unconscious influences. Perhaps that the "godlike metaphor” used by Weiner (1992) to characterize human functioning deserves to be replaced or completed by another one which emphasizes the unconscious processes. The “akratic person” (who acts against his/her better judgment to fulfill impulses) described by Greek philosophers could best describes the unconscious process (e.g., Strack \& Deutsch, 2004).

Our results can have several implications for research and applied issues in sport and exercise psychology. For instance, the demonstration that a motivational orientation can be, in part, primed by unconscious factors suggests potentially new ways to motivate athletes. Although subliminal means should not be used in applied settings due to the different ethical problems they present (Dijksterhuis et al., 2005), similar unconscious influences might be used to obtain the same results. For example, if athletes perceive some autonomous related elements 
around them, it can be sufficient to predispose them to use more autonomous motivation for their own endeavors. Insofar as athletes agree, their environment might be structured with this objective in mind. For example, content of speech and coaching material might preferably include elements referring to autonomous motivation to prime athletes with this motivation.

Also, we think that it is important to recognize that the priming of unconscious motivation may also lead to negative outcomes. For instance, the sport context includes a host of extrinsic cues such as fame, popularity, physical appearance, monetary prize, and so on. Since all of these variables are susceptible to activate controlled motivation, it is therefore plausible that both coaches and athletes may end up with controlled motivation without being aware of it. Although it may be difficult to minimize the salience of these cues, it is still important to recognize that they are a part of the sport system (through the media and advertisement) and that athletes could be primed without their awareness.

Our results also have important methodological implications. During the funneled debriefing, all participants said that their involvement in the task was the result of their own choice. As these statements illustrated, people sometimes seem unaware of the origin of their behavior or involvement in an activity - a point that was suggested by Nisbett and Wilson (1977) several years ago. Wegner and Wheatley (1999) even indicated that the conscious system often tends to appropriately and to rationally (but falsely) justify unconscious responses. Such observations should lead motivational researchers to raise questions about the validity of the explicit measures that are used in motivational studies as such measures can sometimes ask more than participants really know (Nisbett \& Wilson, 1977). Implicit measures (i.e., those which occur in an automatic fashion, see De Houwer, Teige-Mocigemba, Spruyt, \& Moors, in press) that take unconscious influences more into account could therefore be added to gain a more 
comprehensive view of motivational determinants. For example, Lévesque and Pelletier (2003) reported that an implicit measure of motivation (i.e., chronic motivation) was more related to behavior whereas self-reported motivation was more related to intention.

Lastly, we think that athletes and coaches might benefit from some of the qualities of the unconscious system that can optimize performance and training. Since the unconscious system is really efficient, it would be very interesting to entrust as many tasks as possible to this system, saving many cognitive resources for the task of interest. Thus, athletes might avoid choking by being less distracted by thoughts which are not related to their motor task. Nevertheless, research on unconscious processes is still in its infancy and future work is needed to fully understand both how unconscious motivational orientations could be primed and what consequences could follow from unconscious motivation when compared with conscious motivation. 


\section{Acknowledgments}

The authors would like to thank Hannah Davis Marchand for her helpful feedback on this article. 


\section{References}

Aarts, H., Chartrand, T. L., Custers, R., Danner, U., Dik, G., Jefferis, V. E., \& Cheng, C. M. (2005). Social stereotypes and automatic goal pursuit. Social Cognition, 23, 465-490.

Ajzen, I. (1991). The theory of planned behavior. Organizational Behavior and Human Decision Processes, 50, 179-211.

Ajzen, I. (2002). Residual effects of past on later behavior: Habituation and reasoned action perspectives. Personality and Social Psychology Review, 6, 107- 122.

Astrand, P. O., \& Rodahl, K. (1986). Textbook of Work Physiology. Singapore: McGraw-Hill Book Company.

Bandura, A. (1986). Social foundations of thought and action: A social cognitive theory. Englewood Cliffs, NJ: Prentice-Hall.

Bargh, J. (1997). The automaticity of everyday life. In R. J. Wyer (Ed.), The automaticity of everyday life: Advances in social cognition (Vol. 10, pp. 1-61). Mahwah: NJ: Erlbaum.

Bargh, J., \& Chartrand, T. (2000). The mind in the middle: A practical guide to priming and automaticity research. In H. T. Reis \& C. M. Judd (Eds.), Handbook of research methods in social and personality psychology (pp. 253-285). NY: Cambridge University Press.

Bargh, J. A., Gollwitzer, P. M., Lee-Chai, A. Y., Barndollar, K., \& Troetschel, R. (2001). The automated will: Nonconscious activation and pursuit of behavioral goals. Journal of Personality and Social Psychology, 81, 1014-1027.

Boiché, J., Sarrazin, P., Grouzet, F. M., Pelletier, L. G., \& Chanal, J. (2008). Students' motivational profiles and achievement outcomes in physical education: A selfdetermination theory. Journal of Educational Psychology, 100, 688-701. 
Brauer, M., \& McClelland, G. (2005). L'utilisation des contrastes dans l'analyse des données: comment tester des hypothèses spécifiques dans la recherche en psychologie? [The use of contrasts in data analysis: How to test specific hypotheses in psychological research?]. L'année Psychologique, 105, 273-305.

Carver, C. S., \& Scheier, M. F. (1998). On the self regulation of behavior. NY: Cambridge University Press.

Chaiken, S., \& Trope, Y. (1999). Dual-process theories in social psychology. New York: Guilford Press.

Chartrand, T. L., \& Bargh, J. A. (1996). Automatic activation of social information processing goals: Nonconscious priming reproduces effects of explicit conscious instructions. Journal of Personality and Social Psychology, 71, 464-478.

De Houwer, J., Teige-Mocigemba, S., Spruyt, A., \& Moors, A. (in press). Implicit measures: A normative analysis and review. Psychological Bulletin.

Deci, E. L., \& Ryan, R. (1985). Intrinsic motivation and self-determination in human behavior. New York: Plenum Press.

Dijksterhuis, A., Aarts, H., \& Smith, P. K. (2005). The power of subliminal: On subliminal persuasion and other potential application. In R. Hassin, J. Uleman \& J. Bargh (Eds.), The new unconscious (pp. 77-106). New York: Oxford University Press.

Dijksterhuis, A., \& Bargh, J. A. (2001). The perception-behavior express-way: Automatic effects of social perception on social behavior. In M. P. Zanna (Ed.), Advances in Experimental Social Psychology (Vol. 33, pp. 1-40). New York: Academy Press.

Dijksterhuis, A., Bos, M. W., Nordgren, L. F., \& van Baaren, R. B. (2006). On making the right choice: The deliberation-without-attention effect. Science, 311, 1005-1007. 
Dixon, N. F. (1981). Preconscious processing. New York: Wiley.

Epstein, S. (1994). Integration of the cognitive and the psychodynamic unconscious. American Psychologist, 49, 709-724.

Ferguson, M. J., Hassin, R., \& Bargh, J. (2007). Implicit motivation: Past, present, and future. In J. Shah \& W. Gardner (Eds.), Handbook of motivational science. New York: Guilford.

Gillath, O., Mikulincer, M., Birnbaum, G., \& Shaver, P. R. (2008). When sex primes love: Subliminal sexual priming motivates relational goal pursuit. Personality and Social Psychology Bulletin, 34, 1057-1069.

Gillet, N., Rosnet, E., \& Vallerand, R. J. (2008). Développement d’une échelle de satisfaction des besoins fondamentaux en contexte sportif. Revue Canadienne des Sciences du Comportement, 40, 230-237.

Hagger, M. S., \& Chatzisarantis, N. L. (2007). Intrinsic motivation and self-determination in exercise and sport. Champaign, IL: Human Kinetics.

Higgins, E. T. (1996). Knowledge activation: Accessibility, applicability and salience. In E. T. Higgins \& A. W. Kruglanski (Eds.), Social Psychology: Handbook of basic principles (pp. 133-168). NY: The Guilford Press.

Hodgins, H. S., Yacko, H., \& Gottlieb, E. (2006). Autonomy and Nondefensiveness. Motivation and Emotion, 30, 283-293.

Lévesque, C., Copeland, K., \& Sutcliffe, R. (2008). Conscious and non conscious processes: Implications for self-determination theory. Canadian Psychology, 49, 218-224.

Lévesque, C., \& Pelletier, L. G. (2003). On the investigation of primed and chronic autonomous and heteronomous motivational orientation. Personality and Social Psychology Bulletin, 29, 1570-1584. 
Lieberman, M. D. (2007). The X- and C-systems: The neural basis of automatic and controlled social cognition. In E. Harmon-Jones \& P. Winkelman (Eds.), Fundamentals of Social Neuroscience (pp. 290-315). New York: Guilford.

Locke, E. A., \& Latham, G. P. (1990). A theory of goal setting and task performance. Englewood Cliffs, NJ: Prentice Hall.

Macrae, C. N., \& Johnston, L. (1998). Help, I need somebody: Automatic action and inaction. Social Cognition, 16, 400-417.

Mc Clelland, D. C., Koestner, R., \& Weinberger, J. (1989). How do self-attributed and implicit motives differ? Psychological Review, 96, 690-702.

Merikle, P. M., \& Daneman, M. (1998). Psychological investigations of unconscious perception. Journal of Consciousness Studies, 5, 5-18.

Metcalfe, J., \& Mischel, W. (1999). A hot/cool system analysis of delay of gratification: Dynamics of willpower. Psychological Review, 106, 3-19.

Nisbett, R., \& Wilson, T. (1977). Telling more than we can know: Verbal reports on mental processes. Psychological Review, 84, 231-259.

Norman, D. A., \& Shallice, T., (1986). Attention to action: Willed and automatic control of behaviour. In R. J. Davidson, G. E. Schwartz \& D. Shapiro (Eds.), Consciousness and self-regulation: Advances in research and theory: Plenum Press.

Ntoumanis, N. (2005). A prospective study of participation in optional school physical education using a self-determination theory framework. Journal of Educational Psychology, 97, 444-453. 
Pelletier, L. G., Fortier, M. S., Vallerand, R. J., \& Briere, N. (2001). Associations among perceived autonomy support, forms of self-regulation, and persistence: A prospective study. Motivation and Emotion, 25, 279-306.

Rosenthal, R., \& Rosnow, R. L. (2008). Essentials of behavioral research: Methods and data analysis (Vol. 3rd). McGraw: Hill.

Ryan, R. M. (1982). Control and information in the intrapersonal sphere: An extension of cognitive evaluation theory. Journal of Personality and Social Psychology, 43, 450-461.

Ryan, R. M., \& Connell, J. P. (1989). Perceived locus of causality and internalization. Journal of Personality and Social Psychology, 57, 749-761.

Sarrazin, P., Vallerand, R. J., Guillet, E., Pelletier, L. G., \& Cury, F. (2002). Motivation and dropout in female handballers: A 21-month prospective study. European Journal of Social Psychology, 32, 395-418.

Sarrazin, P., Roberts, G., Cury, F., Biddle, S., \& Famose, J. (2002). Exerted effort and performance in climbing among boys: The influence of achievement goals, perceived ability, and task difficulty. Research Quarterly for Exercise and Sport, 73, 425-436.

Shiffrin, R. M., \& Dumais, S. T. (1981). The development of automatism. In R. J. Anderson (Ed.), Cognitive skills and their acquisition. Hillsdale, NJ: Lawrence Erlbaum.

Strack, F., \& Deutsch, R. (2004). Reflective and impulsive determinants of social behavior. Personality and Social Psychology Review, 8, 220-247.

Tabachnik, B. G., \& Fidell, L. S. (2006). Using Multivariate Statistics (5th Ed.). NY: Harper \& Row. 
Uleman, J., Newman, L., \& Moskowitz, G. (1996). People as flexible interpreters: Evidence and issues from spontaneous trait inference. In M. P. Zanna (Ed.), Advances in experimental social psychology. San Diego: Academic Press.

Vallerand, R. J., \& Fortier, M. S. (1998). Measures of intrinsic and extrinsic motivation in sport and physical activity: A review and critique. In J. L. Duda (Ed.), Advances in sport and exercise psychology measurement (pp. 81-101). Morgantown: Fitness Information Technology, Inc.

Vallerand, R. J., \& Losier, G. F. (1999). An integrative analysis of intrinsic and extrinsic motivation in sport. Journal of Applied Sport Psychology, 11, 142-169

Vansteenkiste, M., Simons, J., Soenens, B., \& Lens, W. (2004). How to become a persevering exerciser? Providing a clear, future intrinsic goal in an autonomy supportive way. Journal of Sport \& Exercise Psychology, 26, 232-249.

Wegner, D. M., \& Wheatley, T. P. (1999). Apparent mental causation: Sources of the experience of will. American Psychologist, 54, 480-492.

Weiner, B. (1992). Human motivation: Metaphors, theories, and research. Newbury Park, CA: SAGE. 
Table 1

Zero-Order Correlations Among All Dependent Variables

\begin{tabular}{lccccc}
\hline \multicolumn{1}{c}{ Measures } & 2. & 3. & 4. & 5. & 6. \\
\hline 1. Performance & .09 & .14 & .08 & $.21 \dagger$ & .17 \\
2. Perseverance & - & .05 & $.28 *$ & .10 & .13 \\
3. Free choice period & & - & .10 & $.20 \dagger$ & .16 \\
4. Effort & & & - & .14 & .05 \\
5. Interest/enjoyment & & & & - & $.72^{* *}$ \\
6. Autonomy satisfaction & & & & & - \\
\hline
\end{tabular}

Note: $\dagger p<.10 ;{ }^{*} p<.05 ;{ }^{* *} p<.01$.

Table 2

Means (M) and Standard-Deviation (SD) as a Function of Priming Condition

\begin{tabular}{lcccccc}
\hline & \multicolumn{7}{c}{ Priming condition } \\
& \multicolumn{2}{c}{$\begin{array}{c}\text { Controlled } \\
\text { Motivation }\end{array}$} & \multicolumn{2}{c}{ Neutral } & \multicolumn{2}{c}{$\begin{array}{c}\text { Autonomous } \\
\text { Motivation }\end{array}$} \\
& $M$ & $S D$ & $M$ & $S D$ & $M$ & $S D$ \\
\hline Performance (rpm) & 5463 & 2436 & 6038 & 2062 & 6908 & 2196 \\
Persistence (s) & 721 & 100 & 734 & 143 & 785 & 41 \\
Free-choice period (s) & 11 & 25 & 12 & 20 & 71 & 85 \\
Effort (\%) & 13.5 & 7.6 & 16.0 & 7.6 & 18.6 & 7.9 \\
Interest/enjoyment & 4.2 & 1.3 & 4.7 & 1.1 & 5.1 & 1.1 \\
Autonomy satisfaction & 2.0 & 1.4 & 2.4 & 1.4 & 3.3 & 1.1 \\
\hline
\end{tabular}

Note: rpm = rotation per minute. 
Table 3.

Hierarchical Multiple Regression Analyses Predicting Performance, Persistence, Free-choice Period, Effort, Interest/Enjoyment and Autonomy Satisfaction

\begin{tabular}{|c|c|c|c|c|c|c|}
\hline Variables & $\beta$ & $t$ & $F$ & $\mathrm{R}^{2}$ & $\begin{array}{c}F \\
\text { change }\end{array}$ & $\begin{array}{c}\mathrm{R}^{2} \\
\text { change }\end{array}$ \\
\hline \multicolumn{7}{|l|}{ Predicting Performance } \\
\hline Step 1 & & & $4.96^{*}$ & .07 & & \\
\hline Linear contrast & .26 & $2.23^{*}$ & & & & \\
\hline Step 2 & & & 2.48 & .07 & $0.07 n s$ & .001 \\
\hline Linear contrast & .26 & $2.21 *$ & & & & \\
\hline Quadratic contrast & .03 & 0.26 & & & & \\
\hline \multicolumn{7}{|l|}{ Predicting Persistence } \\
\hline Step 1 & & & $4.55^{*}$ & .06 & & \\
\hline Linear contrast & .25 & $2.13^{*}$ & & & & \\
\hline Step 2 & & & 2.52 & .07 & $0.52 n s$ & .007 \\
\hline Linear contrast & .25 & $2.13^{*}$ & & & & \\
\hline Quadratic contrast & .08 & 0.71 & & & & \\
\hline \multicolumn{7}{|l|}{ Predicting Free-choice period } \\
\hline Step 1 & & $3.35^{* *}$ & $11.24 * *$ & .14 & & \\
\hline Linear contrast & .37 & & & & & \\
\hline Step 2 & & $3.42^{* *}$ & $7.22 * *$ & .18 & $2.89 n s$ & .035 \\
\hline Linear contrast & .38 & 1.71 & & & & \\
\hline Quadratic contrast & .19 & & & & & \\
\hline \multicolumn{7}{|l|}{ Predicting Effort } \\
\hline Step 1 & & $2.55^{*}$ & $6.51 *$ & .09 & & \\
\hline Linear contrast & .29 & & & & & \\
\hline Step 2 & & $2.53^{*}$ & $3.23 *$ & .09 & $0.04 n s$ & .001 \\
\hline Linear contrast & .29 & -0.20 & & & & \\
\hline Quadratic contrast & -.02 & & & & & \\
\hline Predicting Interest/Enjoyment & & $2.70^{* *}$ & & & & \\
\hline Step 1 & & & $7.32 * *$ & .10 & & \\
\hline Linear contrast & .31 & $2.69 * *$ & & & & \\
\hline Step 2 & & -0.05 & $3.61^{*}$ & .10 & $0.00 \mathrm{~ns}$ & .000 \\
\hline Linear contrast & .31 & & & & & \\
\hline Quadratic contrast & -.01 & & & & & \\
\hline Predicting Autonomy satisfaction & & $2.46^{*}$ & & & & \\
\hline Step 1 & & & $6.06^{*}$ & .08 & & \\
\hline Linear contrast & .28 & $2.48^{*}$ & & & & \\
\hline Step 2 & & 1.20 & $3.76^{*}$ & .10 & $1.43 n s$ & .02 \\
\hline Linear contrast & .29 & & & & & \\
\hline Quadratic contrast & .14 & & & & & \\
\hline
\end{tabular}

